\title{
2015 Proceedings
}

Santa Fe, New Mexico

\section{Oversea direct buying in the apparel industry: A case of Korean Jicgoo}

\author{
Kyung Lee, Iowa State University
}

Key words: Overseas direct purchase, Jicgoo, apparel industry, FTA, on-line retailer

Introduction. Purchasing goods directly from oversea on-line retailers has become popular in Asian countries, especially in Korea. This kind of new consumption pattern is called oversea direct purchase (ODP) or Jicgoo and a buyer making ODP is named Jicgoojok in Korean neologism (Kim, 2014). ODP has been a serious challenge to local merchants because of price competitiveness and wider choices of products offered by oversea on-line retailers. US-Korea Free trade agreements (FTA) play an essential role to establish the global infrastructure for the US apparel firms' economic activities, consequentially, overall market size of ODP in Korea presented double digit growth consistently for the last five years and hit $\$ 1.54$ billion (USD) in 2014, and 73.5 percent of Jicgoojok bought from the US retailers and one fourth of their purchases were apparels and footwear in 2014 (Korea Customs Service, 2014). It is clear that ODP generates profits and new business opportunities for oversea retailers, especially the ones in the US apparel industry. However, there are some barriers for the US retailers to enter Korean ODP market such as issues in culture, purchase systems, and institutional policies. Currently, there is a lack of literature describing ODP in the apparel industry. Therefore, the purpose of this study was to review literature on Korean ODP and the US apparel industry. Specifically, the objectives of the review were as stated: (a) explore the current state of ODP practice in Korea, (b) examine antecedents to ODP market growth for the US retailers, and (c) analyze the roles the FTA plays on ODP, and (d) suggest future directions for research of ODP in the apparel industry.

Method. The status of ODP in the apparel industry was examined by two means, first, documents provided by the Korea Customer Agency (KCA), a governmental organization established for consumer protection, and second, a comprehensive review of literature. KCA has provided references and data including: (a) surveys on consumer satisfaction in ODP, (b) research on major on-line retailers in ODP, (c) current ODP status and improvement plan, and (d) analysis of ODP consumer complains. Previous studies conducted on ODP in other industries such as electronics or consumer goods were reviewed thoroughly to analyze compatibilities and disparities of the apparel industry. The review was complemented by the contents in different sources ranging from online and off-line channels that illustrate the context in the apparel industry such as: (a) case studies of various companies in ODP business (e.g., Agencies of shipping, purchasing and custom service), (b) websites including major US on-line retailers (e.g., Amazon, Ebay, Shopbop and etc.) ; governmental organizations and agencies (e.g., International Trade Administration, Office of US Trade Representative, Ministries of Foreign Affairs and etc.) ; economy section of major news sources (e.g., Bloomberg, Economist, Korea Herald and etc.).

Results. The results of the review of literature confirm a lack of academic research about ODP in the apparel industry. Review of evidential documents of KCA illustrates that there are problems related to technology infrastructure of on-line retailers that need to be resolved, such as issues related to the payment systems, address recognition, system security and etc. Political

Page 1 of 2 
institutional matters in Korea and the US turned out to be one of the significant causes of consumer complaints, such as incompatibility in import and export policies and regulations between two countries. Primary consumer motivations of ODP were lower prices and larger product selections, followed by more unique style choices, expedited shipping, good customer service, and etc. Payment system incompatibilities and financial insecurities were the most crucial barriers against purchase decisions followed by language barriers. Previous studies regarding ODP in other industries like electronics and consumer goods substantiated that research on ODP is also insufficient in other industries and most of studies were undertaken in three main areas: (a) FTA and manufacturing industry, (b) ODP's economic impact on import and export goods, and (c) psychological factors on consumer behavior in ODP. The literatures provided evidences that US-Korea FTA positively influences to ODP business across-industry, mainly for lower prices by reduced import duty and moderated legal regulations. Among the US on-line retailers, Jicgoojok had strong preference to large companies such as Amazon or Ebay, however, they became favorable to mid to small retailers like Zappos, as ODP has been an experienced practice for Korean consumers for about a half a decade now.

Conclusions. The findings of this study suggest that future research on the ODP in the apparel industry should answer the following questions: (a) What are the solutions to resolve hindrances for consumer purchase decisions in ODP? (b) What are the antecedents to boost ODP market growth?, (c) What kind of trade agreements will be needed for future market changes?, and (d) What institutional strategies should be provided for foreign on-line retailers? It would be important for these questions to be answered for two reasons: first is to enhance consumer satisfaction in ODP, second is to increase new business opportunities for on-line retailers, especially medium to small entrepreneurs and textile and apparel manufacturers. It is critical for the apparel firms to acquire expertise to overcome barriers to enter the new markets, particularly the ones consisted of unique technological elements such as ODP. Hence, executives of apparel firms should recognize that understanding the factors associated with motivations and resistances of consumers determines the competencies of the firms and sustainable growth overtake competitors. Administrators and policy makers should reinforce trade agreements with foreign countries to promote economic activities between their firms in the global market. Future research should be also conducted to find the impact of ODP in different types of on-line retailers, such as department stores, specialty stores, and designer brands to verify their competitiveness in the market.

\section{References}

Cherry, J. (2012). Upgrading the 'software': The EU-Korea Free Trade Agreement and sociocultural barriers to trade and investment. The Pacific Review, 25(2), 247-268.

Kim, C. (2014). Koreans find overseas bargains a click away. Bloomberg. Retrieved from http://www.bloomberg.com/bw/articles/2014-05-15/koreans-shop-the-web-for-overseasbargains.

Korea Customs Service. (2014). Continuous growth of oversea direct purchase. Retrieved from http://www.customs.go.kr/kcshome/cop/bbs/selectBoard.do?layoutMenuNo=294\&bbsId $=$ BBSMSTR_1018\&nttId=2721. 